\title{
Sequence of Events during Rapid Germination of Spores of Bacillus cereus
}

\author{
By G. J. DRING AND G. W. GOULD \\ Unilever Research Laboratory, \\ Colworth House, Sharnbrook, Bedford
}

(Accepted for publication 27 November 1970)

Levinson \& Hyatt (I966) showed that the measurable events collectively recognized as spore germination, and previously thought to take place concurrently, occurred in Bacillus megaterium QM BI55I in the following sequence: loss of resistance to heat and mercuric chloride; release of dipicolinic acid (DPA); onset of stainability; darkening of individual spores under phase contrast optics and fall in extinction of spore suspensions. Although the mechanism initiating these changes is not known, Strange \& Dark (1957) and Gould, Hitchins \& King (1966) suggested that they result more or less directly from depolymerization of peptidoglycan in the spore cortex, catalysed by a lytic enzyme which can be extracted from spores of some species and which can be shown to cause germination-like changes in chemically sensitized spores (Gould \& King, 1969). If this is so then the excretion of peptidoglycan fragments would be expected to be one of the earliest determinable events during germination. However, if hydrolysis of peptidoglycan only commences following germination, then excretion of fragments should occur late in the sequence of events. The experiments described here were designed to resolve these possibilities.

Organism. Spores of Bacillus cereus T were grown in G medium (Stewart \& Halvorson, 1953). Peptidoglycan in spores was labelled with generally tritiated 2,6-diaminopimelic acid $\left(\left[{ }^{3} \mathrm{H}\right]\right.$ DAP; Radiochemical Centre, Amersham, Buckinghamshire) by adding [ $\left.{ }^{3} \mathrm{H}\right]$ DAP ( $40 \mu \mathrm{m}$.; specific activity, $9 \mathrm{mCi} / \mathrm{mmole}$ ) and cold lysine (I $\mathrm{mm}$ ) to cultures in the 'granular' stage of growth, just prior to the commencement of sporulation. The presence of excess lysine prevented decarboxylation of the $\left[{ }^{3} \mathrm{H}\right] \mathrm{DAP}$ (Vinter, 1965). Spores were cleaned by centrifuging six times in ice-cold $\mathrm{HCl}(0.03 \mathrm{~N})$ as recommended by Murrell \& Warth (1965), twice in ice-cold distilled water, and stored frozen.

Germination. Spores were activated by heating in water at $70^{\circ}$ for $30 \mathrm{~min}$., washed once in water, then added (about $10^{8} / \mathrm{ml}$.) to the following solution at $30^{\circ}$, to initiate germination: tris (hydroxymethyl amino methane) $+\mathrm{HCl}$ buffer ( $100 \mathrm{mM}, \mathrm{pH} 8 \cdot 0$ ), containing L-alanine $(5 \mathrm{~mm})$ and inosine $(5 \mathrm{~mm})$. Samples were taken at intervals, and the germination process was rapidly halted either by separating spores from the supernatant fraction in about $15 \mathrm{sec}$. by membrane filtration using filter membranes $(0.45 \mu \mathrm{m}$. mean pore size) in Swinney filter holders on syringe barrels (Millipore Corp., Bedford, Massachusetts, U.S.A.), or by adding formaldehyde $(20 \% \mathrm{v} / \mathrm{v})$ and quickly centrifuging.

Analyses. Pellet and supernatant samples were analysed for calcium using an Atomic Absorption Spectrophotometer (Unicam Instruments Ltd, Cambridge). Dipicolinic 
acid (DPA) was determined by the colourimetric method of Janssen, Lund \& Anderson (1958): [3H]DAP-containing material was measured using a liquid scintillation counter (Nuclear Chicago Corp., Illinois, U.S.A.); the extinction of the germinating spore suspensions was followed at $580 \mathrm{~nm}$. using a spectrophotometer (SP 600, Unicam Instruments Ltd); loss of heat resistance was measured by pipetting samples ( $\mathrm{I} \mathrm{ml}$.) of germinating culture at intervals into a larger volume of water ( $100 \mathrm{ml}$.) at $70^{\circ}$, so that the temperature rise was abrupt; spores surviving $30 \mathrm{~min}$. at $70^{\circ}$ were scored as 'ungerminated', and enumerated by poured plate viable counts in nutrient agar.

Processing of results. Analytical results are given up to $10 \mathrm{~min}$. incubation, because no great changes occurred after this time. Values are expressed as percentages as follows (McCormick, 1965):

$$
\frac{V_{t}-V_{t}}{V_{1}-V_{f}} \times 100
$$

where $V_{\mathrm{i}}$ is the initial value, $V_{\mathrm{t}}$ is the value at time $t, V_{\mathrm{t}}$ is the final value (i.e. value at Io $\min$.).

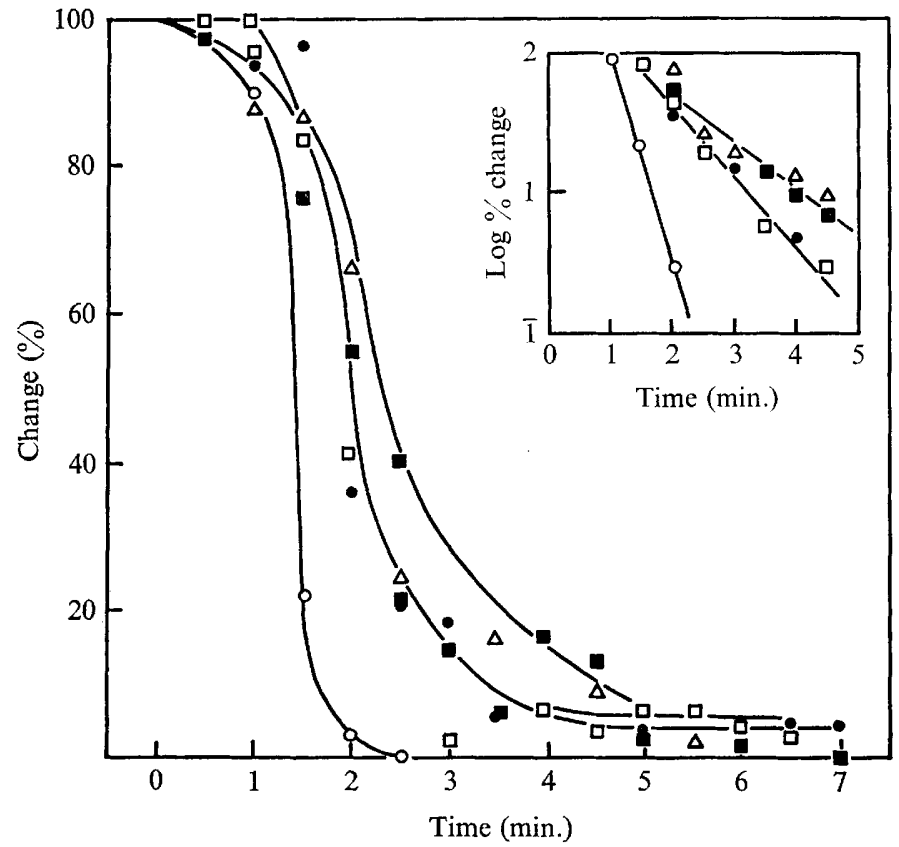

Fig. I. Sequence of events occurring during germination of Bacillus cereus $\mathrm{T}$ spores. Spores were heat-activated and then germinated in L-alanine+inosine as described in the text. The figure shows the following changes occurring during germination: fall in heat resistance $(O)$; loss of dipicolinic acid (O); loss of calcium ( $\square$ ); loss of diaminopimelic acid-containing material ( $\mathbf{D})$; fall in extinction $(\triangle)$. The data is plotted semilogarithmically in the inset to show rate differences of the changes during the exponential phase of germination. (Nearcoincident lines are omitted for clarity.)

The sequence of changes measured during germination is shown in Fig. I. The earliest event was loss of heat resistance ( $50 \%$ complete in $8 \mathrm{I} \mathrm{sec}$.), followed by release of calcium and DPA almost coincidentally ( $50 \%$ complete in II $4 \mathrm{sec}$.), but with some indication of a lag in the excretion of calcium when compared with release of DPA. Release of tritium label, indicative of release of DAP-containing fragments of pepti- 
doglycan, was $50 \%$ complete in $\mathrm{I} 28$ sec., accompanying the fall in extinction $(50 \%$ complete in $132 \mathrm{sec}$.).

Furthermore, semilogarithmic plots of the results over the exponential portion of the curves (Fig. I, inset) illustrates that the rates of change of the earliest events were greater than those of the subsequent events.

The sequence was the same in a number of experiments, whether germination was arrested by rapid membrane filtration or by formaldehyde.

That excretion of peptidoglycan fragments occurred early in germination rather than as a postgerminative event supports the hypothesis that hydrolysis of peptidoglycan in the spore cortex initiates germination. Some lag in excretion would be expected due to the slow diffusion from the germinating spores of the peptidoglycan fragments, which are large, with mean molecular weights (MW) of 10,000 or so (Strange \& Dark, I957); excretion of the low MW spore components calcium and DPA, which one would expect to diffuse rapidly, only preceded excretion of peptidoglycan by about Io sec. Hashimoto, Frieben \& Conti (1969) recently followed the release of hexosamine-containing material from germinating spores as a measure of hydrolysis of peptidoglycan, and found that early excretion occurred in the same sequence as reported here.

The observation that the earliest measurable germination event was loss of spore heat resistance agrees with the observations of others. If loss of heat resistance is the result of hydrolysis of peptidoglycan, then the extent of hydrolysis at this early stage was insufficient to release diffusible fragments into the medium. It is possible that the initial hydrolysis, which cleaves the peptidoglycan backbone (Gould \& King, 1969), was sufficient to destroy the contractile properties of the polymer in the spores (Lewis, Snell \& Burr, 1960) or to destroy some other property essential for the maintenance of heat resistance, without producing diffusible fragments, and that release of peptidoglycan fragments into the medium only occurred after more extensive hydrolysis.

We thank Dr W. G. Murrell for his helpful suggestions and advice.

\section{REFERENCES}

Gould, G. W., Hitchins, A. D. \& KING, W. L. (1966). Function and location of a germination enzyme in spores of Bacillus cereus. Journal of General Microbiology 44, 293-302.

Gould, G. W. \& KING, W. L. (1969). Action and properties of spore germination enzymes. In Spores, vol. 4, pp. 276-286. Edited by L. L. Campbell, Washington, D. C.: American Society for Microbiology.

Hashimoto, T., Frieben, W. R. \& Conti, S. F. (I969). Microgermination of Bacillus cereus spores. Journal of Bacteriology I00, $\mathrm{I}_{3} 85-\mathrm{I} 392$.

JAnssen, F. W., Lund, A. J. \& ANDErson, L. E. (1958). Colorimetric assay for dipicolinic acid in bacterial spores. Science, New York 127, 26-27.

Levinson, H. S. \& Hyatr, M. T. (1966). Sequence of events during Bacillus megaterium spore germination. Journal of Bacteriology 9r, $\mathrm{r} 81 \mathrm{I}-18 \mathrm{I} 8$.

Lewis, J. C., SNell, N. S. \& BurR, H. K. (I960). Water permeability of bacterial spores and the concept of a contractile cortex. Science, New York 132, 544-545.

MCCORMICK, N. G. (1965). Kinetics of spore germination. Journal of Bacteriology 89, I I80-1 I85.

Murrell, W. G. \& Warth, A. D. (1965). Composition and heat resistance of bacterial spores. In Spores, vol. 3, pp. I-24. Edited by L. L.Campbell and H. O. Halvorson, Ann Arbor, Michigan: American Society for Microbiology.

Stewart, B. T. \& Halvorson, H. O. (1953). Studies on the spores of aerobic bacteria. I. The occurrence of alanine racemase. Journal of Bacteriology 65, I60-166. 
Strange, R. E. \& Dark, F. A. (1957). A cell-wall lytic enzyme associated with spores of Bacillus species. Journal of General Microbiology 16, 236-249.

VINTER, V. (1965). Spores of micro-organisms. XVII. The fate of pre-existing diaminopimelic acidcontaining structures during germination and postgerminative development of bacterial spores. Folia Microbiologica, Praha 10, 280-287. 